\title{
Morfologia comparativa e distribuição batimétrica de duas espécies de Ophiuroidea, na regiẫo costeira de Ubatuba
}

\author{
Ana Maria Gouveia MONTEIRO; Margarete de Oliveira REIS* \& Erica Veronica PARDO
}

Departamento de Zoologia, Universidade Estadual Paulista - UNESP

(Caixa Postal 136, 15001-970 - Sao José do Rio Preto, SP, Brasil)

- Abstract: A total of 722 ophiuroids belonging to the species Ophioderma januarii and Ophioplocus januarii was collected on the coast of the State of São Paulo, from October 1985 to July 1987. Measurements of disc diameter of the specimens were ranged from 10,5 to 21,5 mm for Ophioderma januarii and from 2,6 to $21,5 \mathrm{~mm}$ for Ophioplocus januarii. External morphological characteristics of the individuals were observed and growth series were organized to detect possible changes. For Ophioderma januarii variations were found in the shape of the shields, in the number of oral papillas and arms spines, in the color of the dorsal disc surface and in the dorsal arm plates. On Ophioplocus januarii variations were found in primary scales, in the major scales series of the dorsal interradial region of the disc, in the number of scales between the central plate and the edge of the disc, in the shape of the radials and orals shields, in the number of the oral papillas, in the color of the dorsal disc surface and in the dorsal arm plates. Analyses of environmental parameters show that both species were present in areas with distinct environmental conditions. Ophioderma januarii was collected in the coastal region and as far as $36 \mathrm{~m}$ deep and Ophioplocus januarii from 30 to $100 \mathrm{~m}$ deep.

- Descriptors: Morphology, Vertical distribution, Abiotic factors, Ophiuroidea, Ophioderma januarii, Ophioplocus januarii, Ubatuba: SP, Brazil.

- Descritores: Morfologia, Distribuição vertical, Fatores abióticos, Ophiuroidea, Ophioderma januarii, Ophioplocus januarii, Ubatuba: SP, Brasil.

\section{Introdução}

Vários estudos foram realizados com os ofiuróides na costa brasileira, abordando aspectos taxonômicos e de distribuição geográfica das diferentes espécies, entre os recentes, devem ser citados os de Tommasi $(1965,1971$ a, b,c, 1974a, b, 1985), Tommasi \& Abreu (1974), Tommasi \& Oliveira (1976), Moura-Britto (1985), Albuquerque (1986), Monteiro (1987), Manso (1988a,b,c,d, 1989), Tommasi et al. (1988a).

Os ofiuróides Ophioderma januarii e Ophioplocus januarii, das famílias Ophiodermatidae e Ophiuridae,

$\overline{\left({ }^{*}\right) \text { Bolsista }}$ do CNPq. respectivamente, têm sido amostrados com certa freqüência no litoral do Estado de São Paulo e, esporadicamente, em vários pontos da costa brasileira (Rathbun, 1879; Oliveira, 1950; Brito, 1962; Tommasi, 1970 e 1985; Nunes, 1975; Albuquerque, 1986; Monteiro, 1987; Tommasi \& Aron, 1987; Tommasi et al. 1988b).

O presente estudo tem como objetivo principal dar continuidade a trabalhos anteriores realizados com os ofiuróides do litoral norte do Estado de São Paulo por Monteiro (1987), que visam contribuir ao conhecimento da distribuição e morfologia das espécies de ofiuróides que ocorrem nessa regiāo.

Foram efetuados estudos das variações individuais de estruturas morfológicas utilizadas na taxonomia do grupo, com a elaboração de séries de crescimento. A organização de séries de crescimento para os ofiuróides são de extrema valia na identificação das espécies, tendo em vista que muitos caracteres morfológicos usuais na 
taxonomia, sofrem alterações a medida que os indivíduos crescem.

A distribuição dos exemplares de Ophioderma januarii e de Ophioplocus januarii foi relacionada com os parâmetros ambientais medidos no momento da coleta, para a caracterização do ambiente onde vivem.

\section{Material e métodos}

Os ofiuróides foram coletados durante a realização do Projeto Integrado "Ecossistemas Costeiros da Região Tropical Brasileira: Estado de São Paulo", no período de outubro de 1985 a julho de 1987 . Realizou-se quatro cruzeiros oceanográficos semestrais com o N/Oc."Prof. W. Besnard" e coletas trimestrais com o B/Pesq. "Veliger II". Foi estabelecida uma rede de estaçôes com três radiais em profundidades até $50 \mathrm{~m}$ e outras três, entre 50 e100 m (Fig.1). Paralelamente foram realizadas análises hidrográficas em cada estação, com medidas de temperatura e obtenção de amostras de água de fundo para análise da salinidade, oxigênio dissolvido e sedimento, para análise de granulometria, matéria orgânica e calcário.

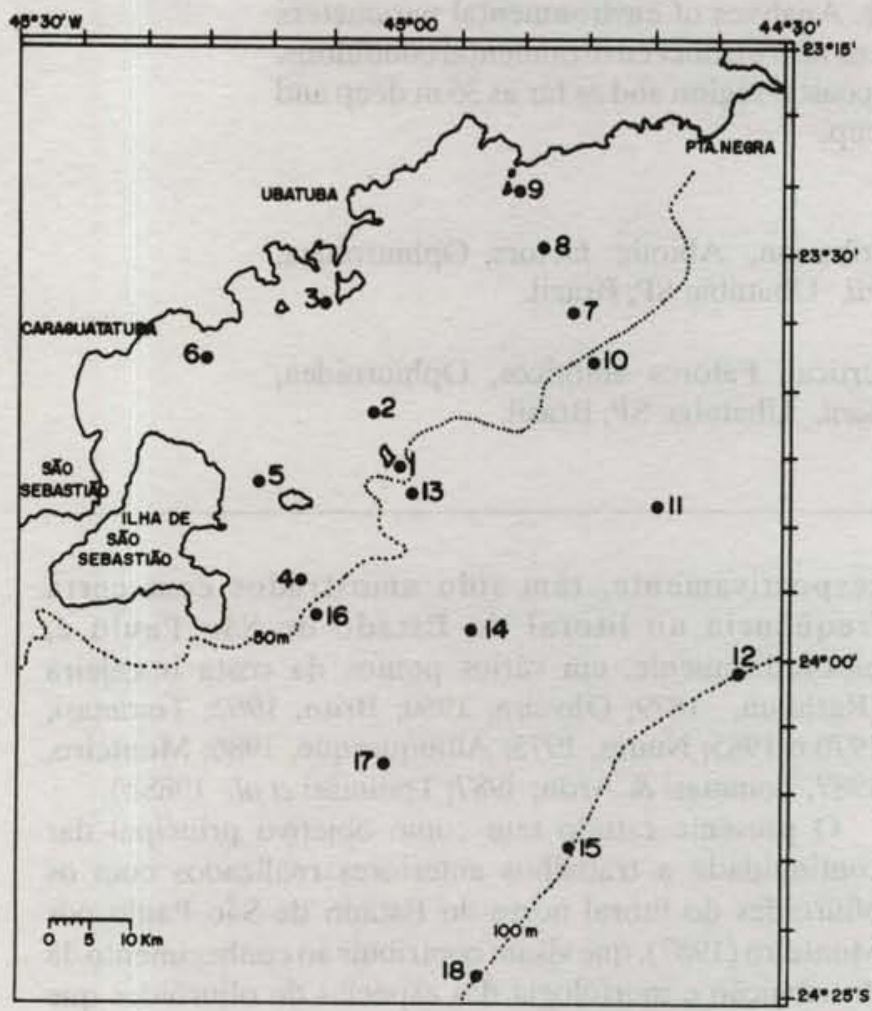

Fig. 1. Mapa da região estudada com a localização das estações de coleta.
O material bentônico foi amostrado com pegador de fundo do tipo van Veen modificado $\left(0,1 \mathrm{~m}^{2}\right.$ de área), draga retangular (malha de 6 e $25 \mathrm{~mm}$ nos dois sacos) e rede-de -arrasto de porta com malha de 20 e $24 \mathrm{~mm}$. Nos laboratórios do Instituto Oceanográfico-USP foi efetuada a triagem dos organismos e os ofiuróides foram acondicionados em frascos e encaminhados ao Departamento de Zoologia, Universidade Estadual Paulista - UNESP, Campus de São José do Rio Preto, onde encontram-se depositados.

Foi efetuada a medida do diâmetro do disco dos exemplares de Ophioderma januarii e de Ophioplocus januarii. Em seguida, os ofiuróides foram submetidos à análise dos caracteres morfológicos externos utilizados na taxonomia, com a verificação das possíveis alteraçōes encontradas em exemplares de diferentes tamanhos. Com base nessas observaçōes, foram organizadas séries de crescimento e posterior esquematização das mesmas com auxílio de câmara clara.

\section{Resultados e discussão}

Do total de ofiuróides amostrados durante a realização do Projeto Integrado, foram analisados 722 exemplares pertencentes às duas espécies em estudo.

A identificação dos exemplares Ophioplocus januarii (Lutken, 1856) e Ophioderma januarii Lutken, 1856 foi efetuada de acordo com Fell (1960) e Tommasi (1970).

Os exemplares foram amostrados, em sua maioria, por rede-de-arrasto. Ophioderma januarii, na estação 2 (10/85), foi obtido em dragagem, o mesmo ocorreu com Ophioplocus januarii, na estação 18 (07/86), embora tenham sido usados em todas estaçōes pegador, draga e rede-de-arrasto. Portanto, verifica-se que essas espécies de ofiuróides, talvez por seu maior tamanho e habilidade de movimentação sobre o substrato, são comumente coletadas com rede-de-arrasto, que amostra uma ampla área.

Embora tenha sido ampla a rede de estaçōes, Ophioderma januarii ocorreu em 16 amostragens de quatro estaçōes, num total de 211 exemplares (Tab. 1) e Ophioplocus januarii, em 10 amostragens de seis estaçôes, num total de 511 exemplares (Tab. 2).

\section{Ophioderma januarii Lutken, 1856}

A distribuição geográfica de Ophioderma januarii compreende Trinidad-Tobago e Brasil (da costa norte à sudeste). Essa espécie tem sido coletada com freqüência no litoral do Estado de São Paulo e no presente estudo, foi amostrada na região da plataforma interna (profundidades inferiores a $50 \mathrm{~m}$ ). 
Tabela 1. Estações de coleta de Ophioderma januarii com as respectivas médias dos diâmetros dos discos dos exemplares

$\begin{array}{lll}\text { ESTACAO DATA } & \text { Ne DE } & \times \quad \text { DIAMETRO } \\ \text { EXEMPLARES } & \text { DO DISCO }(\mathrm{mm})\end{array}$

$\begin{array}{llrl}02 & 10 / 85 \text { (PRIMAVERA) } & 1 & 21,20 \text { * } \\ 09 & 10 / 85 \text { (PRIMAVERA) } & 13 & 15,00 \\ 02 & 01 / 86 \text { (VERÃO) } & 2 & 21,00 \text { * } \\ 09 & 01 / 86 \text { (VERÃO) } & 5 & 16,52 \\ 09 & 04 / 86 \text { (OUTONO) } & 8 & 14,79 \\ 02 & 07 / 86 \text { (INVERNO) } & 1 & 18,90 \text { * } \\ 09 & 07 / 86 \text { (INVERNO) } & 9 & 15,58 \\ 09 & 10 / 86 \text { (PRIMAVERA) } & 126 & 15,78 \\ 02 & 01 / 87 \text { (VERÃO) } & 1 & 19,30 \text { * } \\ 05 & 01 / 87 \text { (VERÃO) } & 3 & 19,18 \text { * } \\ 02 & 04 / 87 \text { (OUTONO) } & 1 & 20,50 \text { * } \\ 09 & 04 / 87 \text { (OUTONO) } & 36 & 15,50 \\ 02 & 07 / 87 \text { (INVERNO) } & 1 & 19,55 * \\ 03 & 07 / 87 \text { (INVERNO) } & 1 & 20,10 \text { * } \\ 05 & 07 / 87 \text { (INVERNO) } & 2 & 20,75 * \\ 09 & 07 / 87 \text { (INVERNO) } & 1 & 16,80 *\end{array}$

* - Valores correspondentes à medida de apenas um exemplar ou a média de dois ou três.

Tabela 2. Estações de coleta de Ophioplocus januarii com as respectivas médias dos diâmetros dos discos dos exemplares

$\begin{array}{ccc}\text { ESTACAO DATA } & \text { N DE } & \times \quad \text { DIAMETRO } \\ \text { EXEMPLARES } & \text { DO DISCO (m) }\end{array}$

\begin{tabular}{llrl}
\hline & & & \\
16 & $12 / 85$ (VERÃO) & 164 & 15,05 \\
17 & $12 / 85$ (VERÃO) & 8 & 16,06 \\
18 & $07 / 86$ (INVERNO) & 127 & 15,38 \\
01 & $10 / 86$ (PRIMAVERA) & 1 & $13,10^{*}$ \\
01 & $01 / 87$ (VERÃO) & 2 & $10,30^{*}$ \\
$1 \mathrm{a}$ & $01 / 87$ (VERÃO) & 9 & 13,95 \\
11 & $07 / 87$ (INVERNO) & 5 & 13,81 \\
17 & $07 / 87$ (INVERNO) & 194 & 11,11 \\
18 & $07 / 87$ (INVERNO) & 1 & $13,75^{*}$ \\
\hline
\end{tabular}

* - Valores referentes à medida de apenas un exemplar ou a média de dois.

As medidas do diâmetro do disco dos exemplares de Ophioderma januarii variaram de 10,5 (Estação 9, em 07/86) a 21,5 mm (Estação 5, em 07/87).
Na Figura 2 observa-se a distribuição dessas medidas em classes de tamanho, sendo que a classe com maior freqüência é a de 14,1 a 16,0 mm. Verifica-se que há um decréscimo na freqüência em direção aos valores menores e aos maiores. Tommasi (1970) obteve valores entre 1,52 e $20,5 \mathrm{~mm}$; Albuquerque (1986), entre 3,5 e $20,0 \mathrm{~mm}$ e Monteiro (1987), entre 11,7 e 22,7 mm.

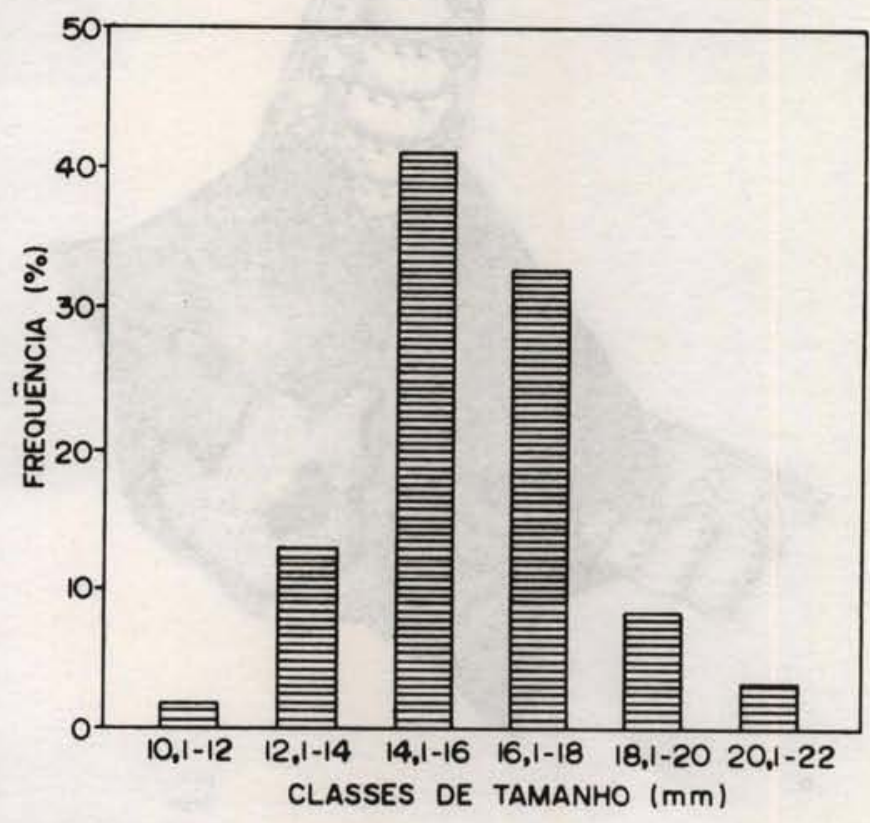

Fig. 2. Distribuição da freqüência de Ophioderma januarii em classes de tamanho do diâmetro do disco.

Considerando-se a média do diâmetro do disco para as estações nas quais foram obtidos mais de cinco exemplares (Tab. 1), esta esteve ao redor de $15,0 \mathrm{~mm}$, exceto na estação $9(01 / 86)$ que foi de $16,52 \mathrm{~mm}$. Nota-se que a estação do ano não parece influenciar o tamanho dos indivíduos, embora o número de exemplares coletados em cada período de amostragem, tenha sido extremamente variável entre os locais de coleta. Na primavera, foram amostrados 140 espécimes, no verão 11 , no outono 45 e no invermo 15 , entretanto, somente na estação $9(10 / 86)$ obteve-se 126.

Foi verificada pouca variação dos caracteres morfológicos externos utilizados na taxonomia para Ophioderma januarii, exceto aquelas mencionadas por Tommasi (1970) e Monteiro (1987), que são mudanças inerentes ao crescimento dos indivíduos, mas que dificultam a identificação para aqueles que não têm familiaridade com a espécie.

Com base no exame detalhado de todos os exemplares dessa espécie, organizou-se uma série de crescimento, utilizando-se para a esquematização animais com diâmetro do disco de 10,5 - 13,5 - 15,5 - 18,5 e 21,5 mm (Figs 3-7). 

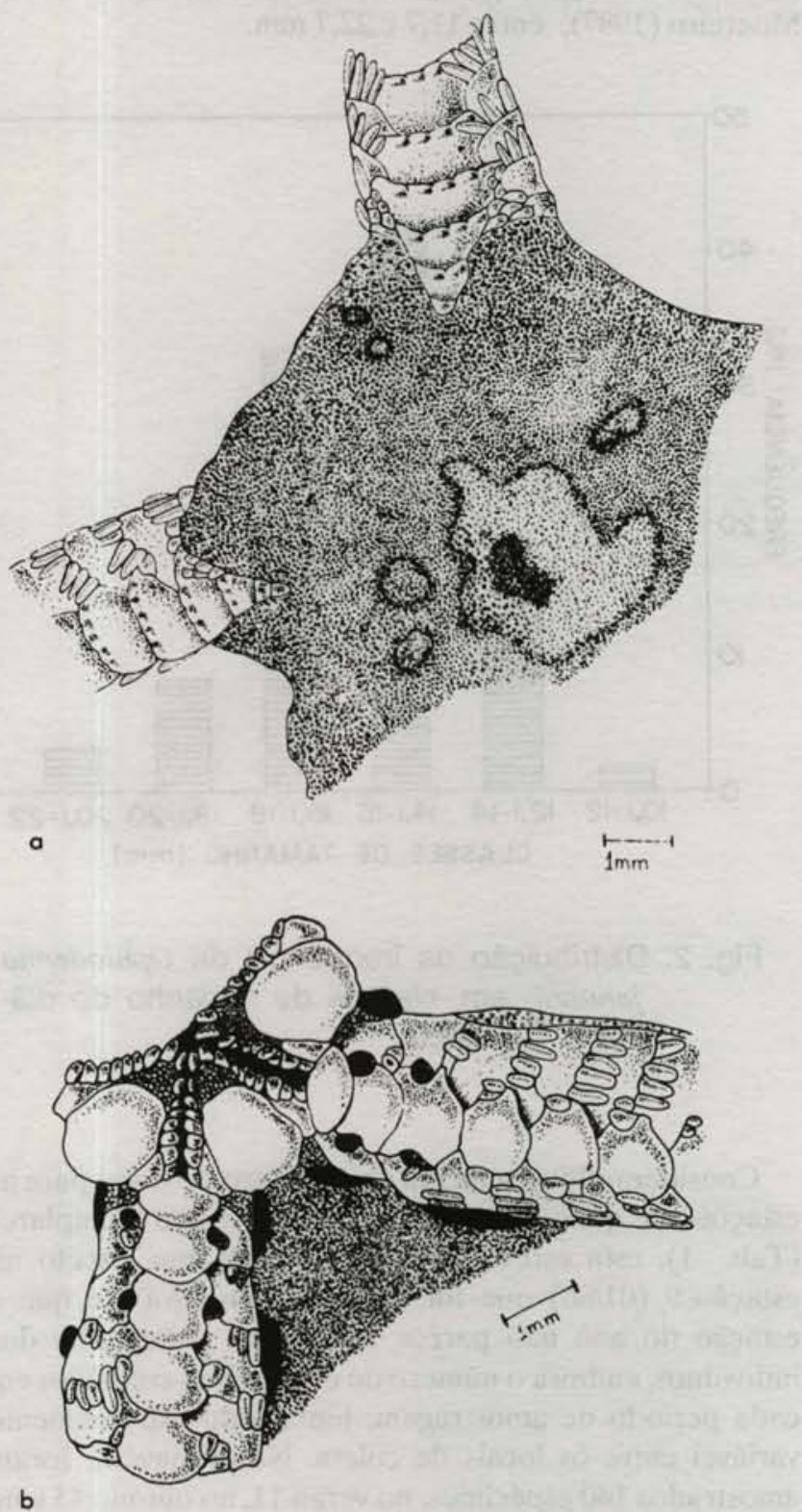

Fig. 3. Vistas dorsal (a) e ventral (b) de Ophioderma januarii com 10,5 mm de diâmetro do disco.

A seguir são relatadas as observaçōes referentes à série de crescimento e aos demais indivíduos estudados, que constituem-se em informaçōes normalmente não encontradas na descrição da espécie.

O disco de Ophioderma januarii é coberto por pequenos grânulos nas regiōes dorsal e ventral. Em alguns
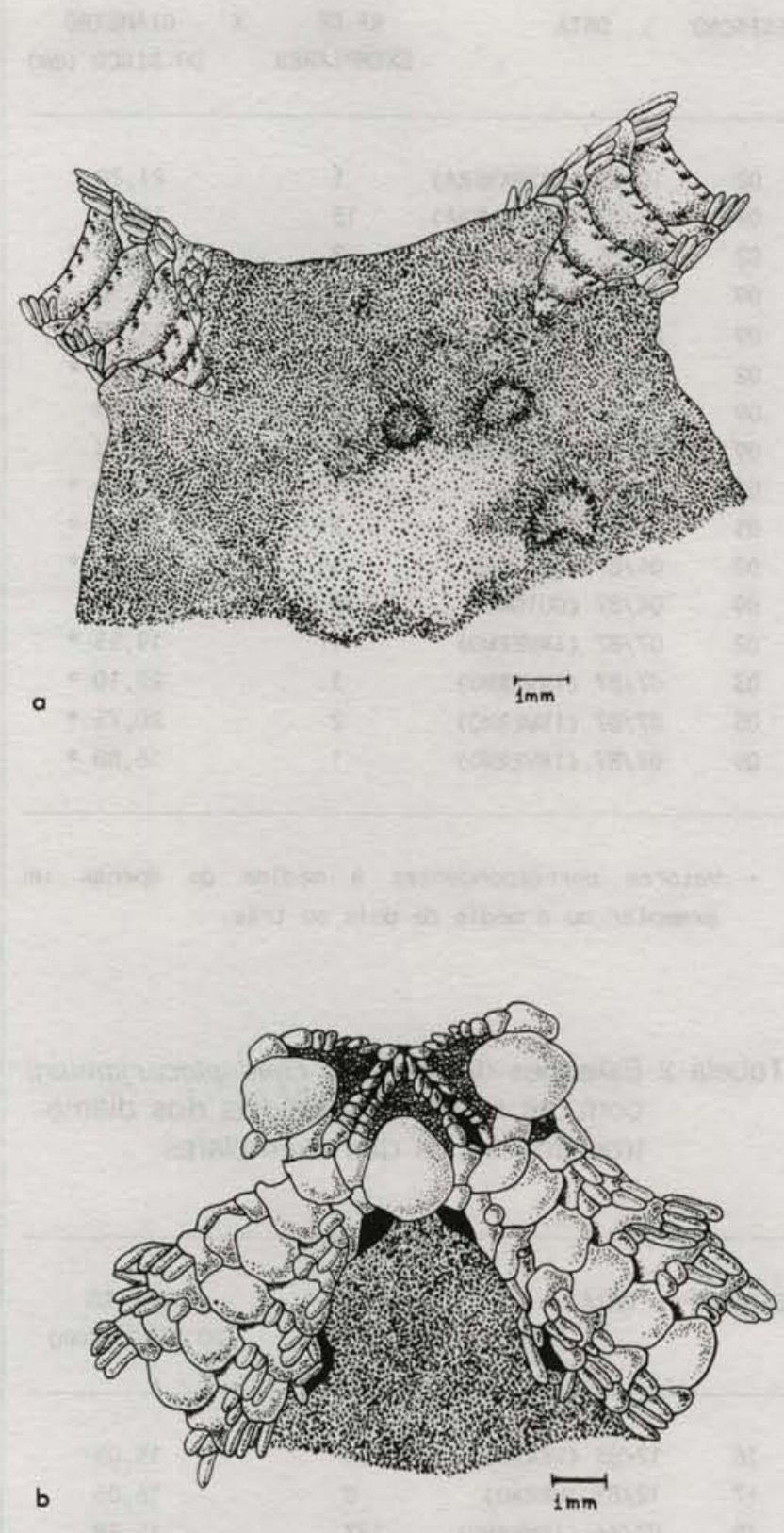

Fig. 4. Vistas dorsal (a) e ventral (b) de Ophioderma januarii com $13,5 \mathrm{~mm}$ de diâmetro do disco.

espécimes não foi verificada essa granulação sobre as escamas em partes do disco, o que pode ser explicado pelo intenso manuseio, desde o momento da coleta. Na inserção dos braços, nota-se a presença de pequenas escamas nuas. 


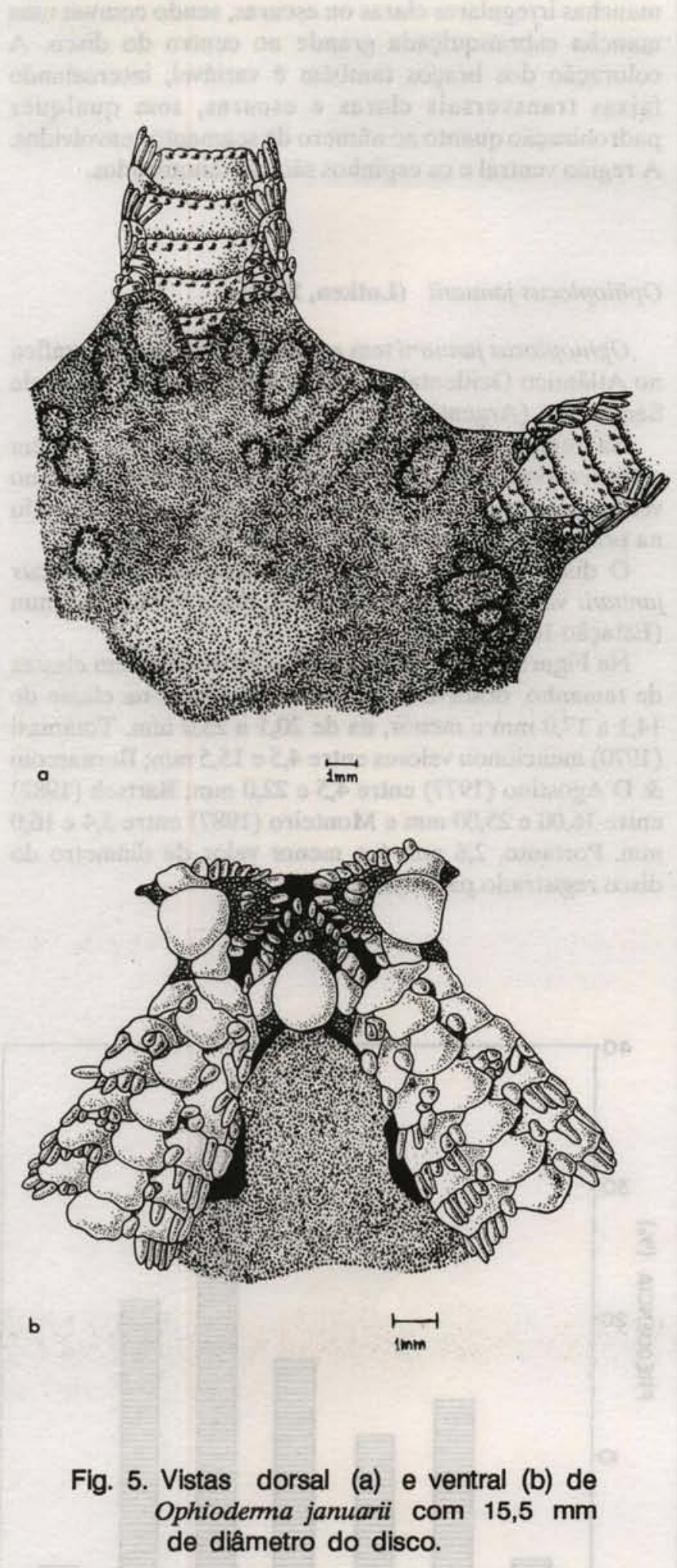

Os escudos radiais alongados estão dispostos lateralmente junto à base dos braços, cobertos por grânulos, mas geralmente sāo possíveis de identificar, particularmente nos exemplares com 18,5 e 21,5 mm, pois constituem pequenas elevaçōes.
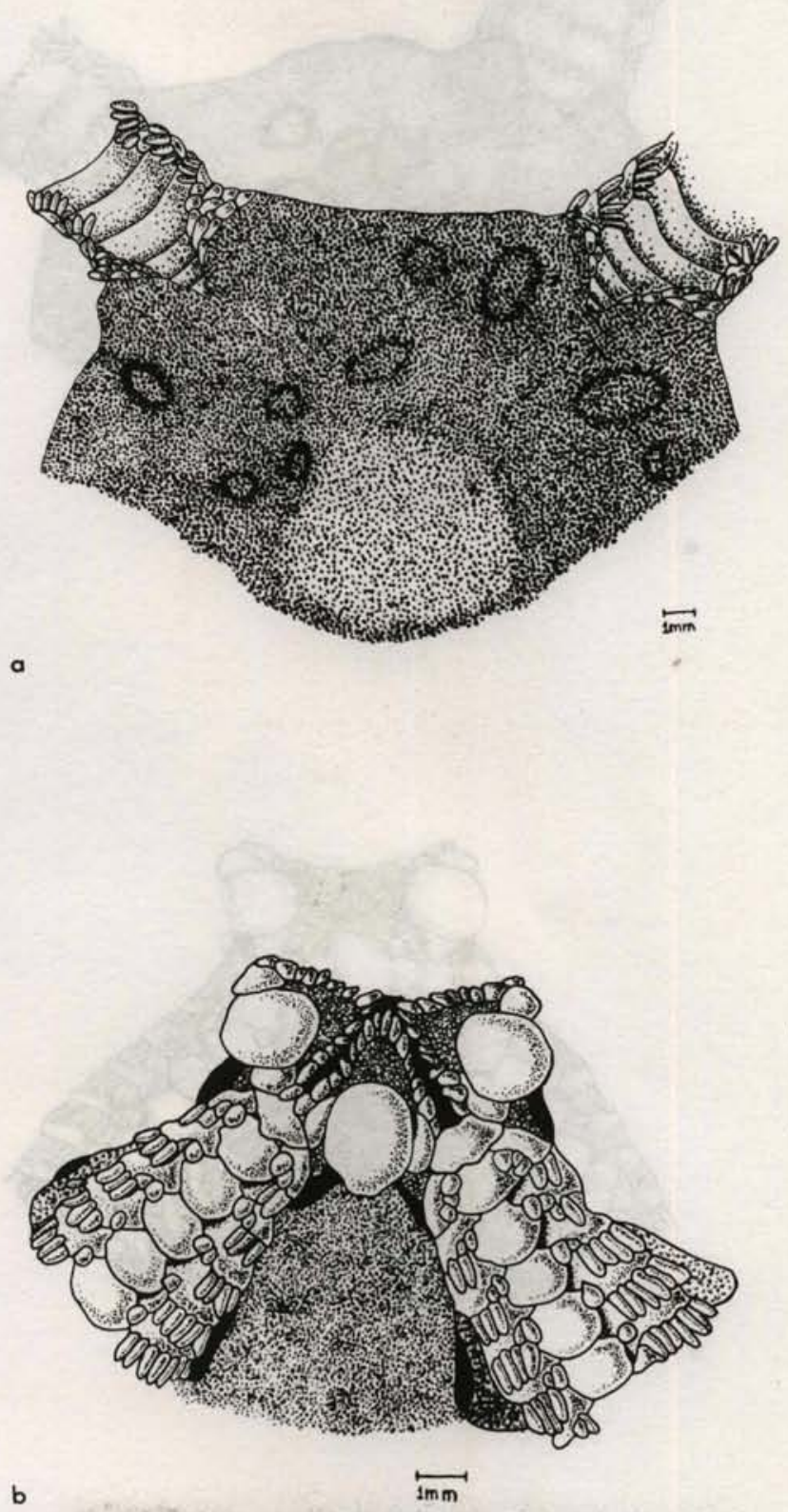

b

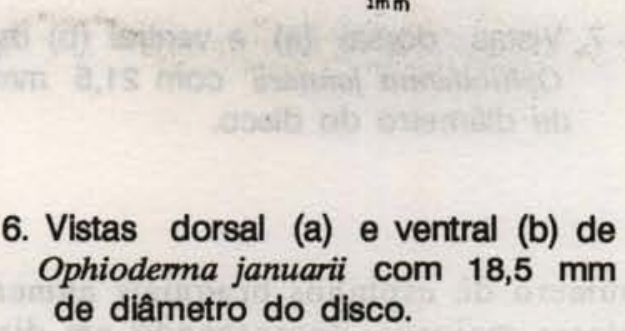

Os escudos orais são bem desenvolvidos, com forma variável, arredondados, ovalados e ovalados com a regiāo proximal levemente afilada.

Papilas orais em número de sẹte a nove, variando em número em uma mesma mandíbula, sendo que as proximais são mais afiladas $\mathrm{e}$ as distais mais alargadas. 

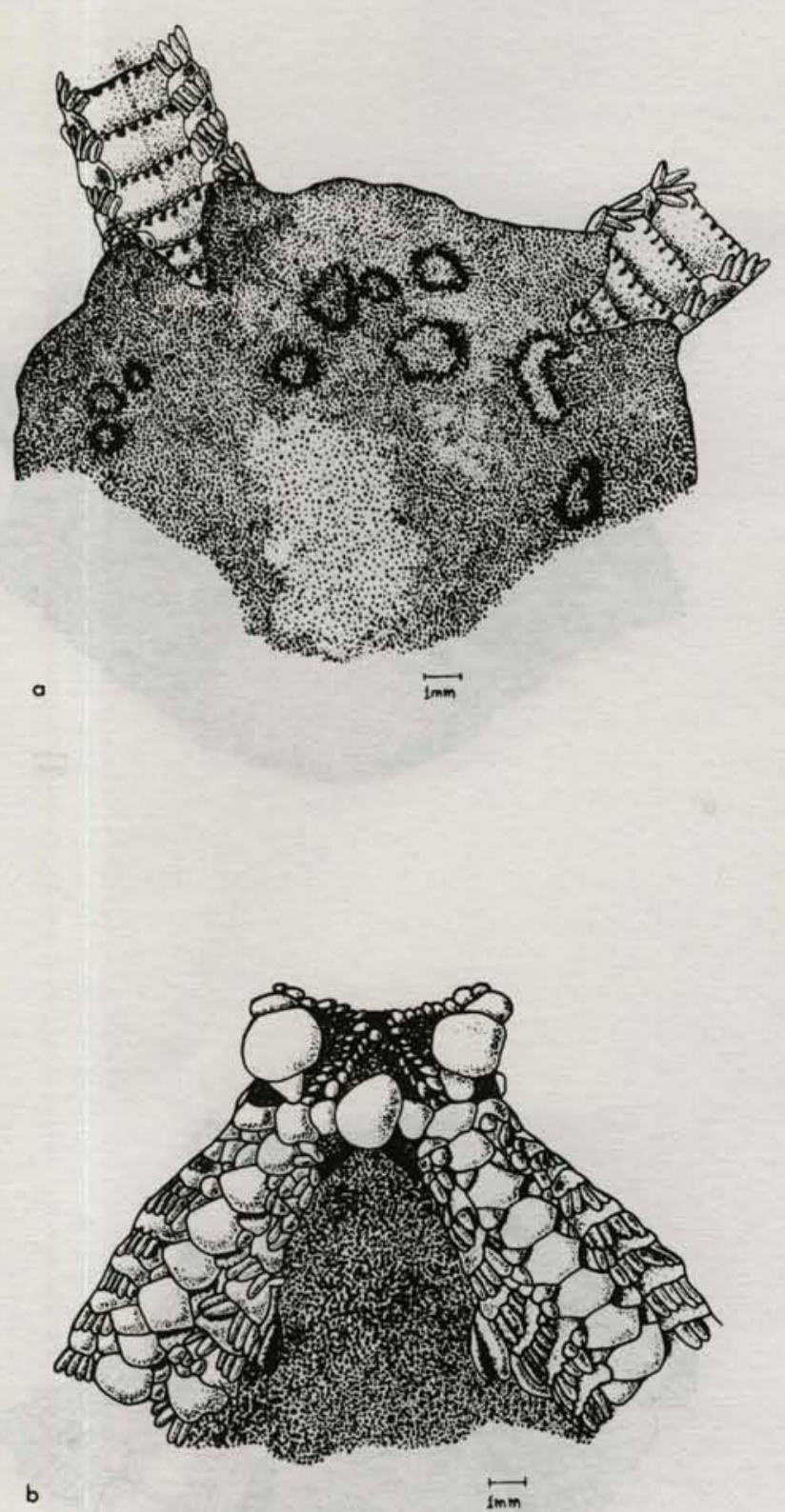

Fig. 7. Vistas dorsal (a) e ventral (b) de Ophioderma januarii com 21,5 mm de diâmetro do disco.

O número de espinhos braquiais aumenta nos exemplares maiores, decrescendo em direção à extremidade do braço, assim, no espécime com 21,5 mm foram observados até 12 espinhos e no de $10,5 \mathrm{~mm}$, até oito espinhos. Estes espinhos braquiais apresentam-se mais longos nos espécimes de maior tamanho.

As placas braquiais dorsais apresentam pequenas estrias escuras na margem distal, sendo mais evidentes nos indivíduos maiores.

A coloração da superfície dorsal do disco variou de verde oliva a castanho amarelado. $\mathrm{O}$ disco apresenta manchas irregulares claras ou escuras, sendo comum uma mancha esbranquiçada grande no centro do disco. A coloração dos braços também é variável, intercalando faixas transversais claras e escuras, sem qualquer padronização quanto ao número de segmentos envolvidos. A região ventral e os espinhos são esbranquiçados.

\section{Ophioplocus januarii (Lutken, 1856)}

Ophioplocus januarii tem ampla distribuição geográfica no Atlântico Ocidental, desde as Antilhas até o Golfo de San Matias (Argentina).

$\mathrm{Na}$ regiāo estudada essa espécie foi amostrada em estaçōes localizadas entre 50 e $100 \mathrm{~m}$ de profundidade, no verâo e no inverno, exceto um exemplar que foi coletado na primavera a $42 \mathrm{~m}$ de profundidade (Tab. 3 ).

O diâmetro do disco dos espécimes de Ophioplocus januarii variou de 2,6 (Estação 17, em 07/87) a 21,5 mm (Estação 18, em 07/86).

$\mathrm{Na}$ Figura 8 os espécimes estão distribuídos em classes de tamanho, observa-se a maior freqüência na classe de 14,1 a $17,0 \mathrm{~mm}$ e menor, na de 20,1 a $23,0 \mathrm{~mm}$. Tommasi (1970) mencionou valores entre 4,5 e $15,5 \mathrm{~mm}$; Bernasconi \& D'Agostino (1977) entre 4,5 e 22,0 mm; Bartsch (1982) entre 16,00 e 25,00 mm e Monteiro (1987) entre 3,4 e 16,0 $\mathrm{mm}$. Portanto, $2,6 \mathrm{~mm}$ é o menor valor de diâmetro do disco registrado para essa espécie.

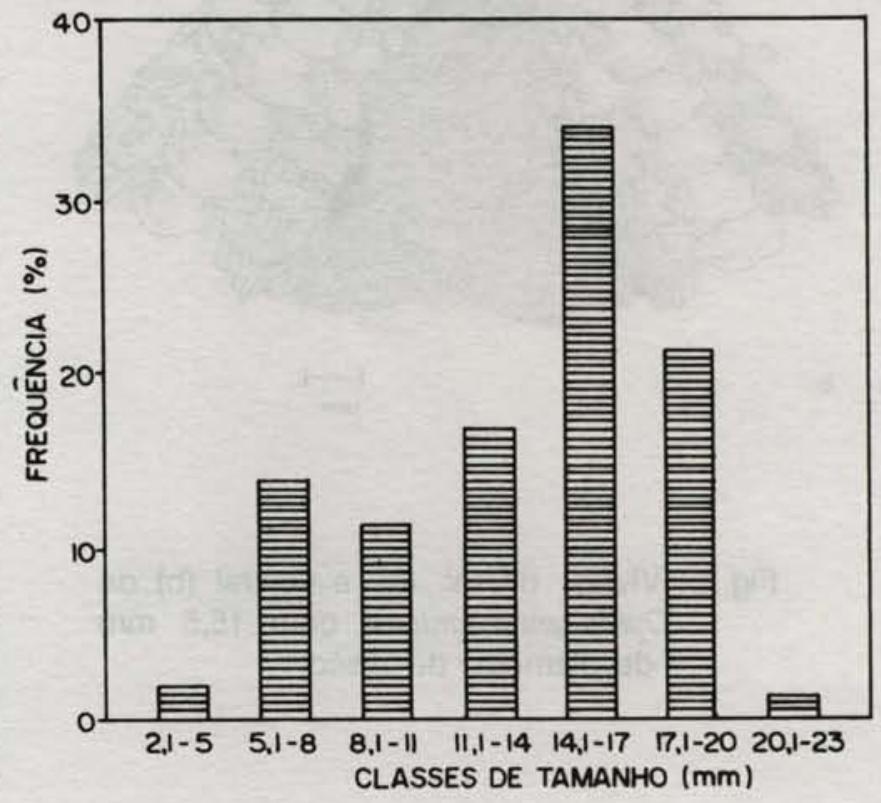

Fig. 8. Distribuição da freqüência de Ophioplocus januarii em classes de tamanho do diâmetro do disco. 
Na estação 1 (01/87) foram amostrados dois exemplares de $O$. januarii e nas estaçōes $1(10 / 86)$ e 18 (07/87), apenas um exemplar em cada uma delas. Ocorreu maior número de especimes pequenos nas estaçōes $18(07 / 86)$ e 17 (07/87), ambas estaçōes foram realizadas no inverno, mas na estação 18 , também foram coletados exemplares grandes, o que elevou a média dos diâmetros para 15,38 mm (Tab. 2).

Infelizmente não foram realizadas coletas na plataforma externa, durante a primavera e outono, para que fossem obtidas amostras de todas as estaçōes do ano.

A análise da abundância dos ofiuróides em uma dada área, geralmente é difícil de ser realizada, porque esses animais podem ficar agrupados, constituindo os chamados "bancos de ofiuróides" e serem abundantes em um local e em outro não. Como exemplo, podem ser citadas as amostragens realizadas em $07 / 87$, onde das nove coletas efetuadas, Ophioplocus januarii foi amostrada em três ou seja, estação 11 com cinco exemplares, 17 com 194 e 18 com 1.

Observando-se os valores apresentados na Tabela 2, onde estão relacionadas as médias dos diâmetros do disco, verificou-se valores superiores a 15,0 mm e inferiores a 14,0 $\mathrm{mm}$, tanto no verão como no inverno. A abundância dos exemplares e a média do diâmetro do disco, não forneceram subsídios para supor qualquer influência sazonal.

Foi observada em Ophioplocus januarii pouca variação dos caracteres morfologicos externos usuais na taxonomia, exceto as mudanças que ocorrem durante o crescimento dos indivíduos e que foram esquematizadas formando uma série de crescimento, utilizando-se animais com 2,5 - 5,0 10,0 - 15,0 e 21,45 mm (Figs 9-13).

A seguir, são destacadas as principais diferenças verificadas no exame dos espécimes durante a esquematização da série de crescimento.

A regiāo dorsal do disco apresenta-se recoberta por escamas irregulares em todos os exemplares. Observou-se que as escamas primárias são evidentes em indivíduos com diâmetro do disco inferior a $10,0 \mathrm{~mm}$, sendo que no menor exemplar (2,5 mm) essas escamas ocupam grande parte da superfície dorsal e encontram-se parcialmente separadas por pequenas escamas. Nota-se, também, no menor espécime a presença de uma fileira de escamas maiores na região interradial, margeada por escamas menores. Esta fileira de escamas está presente, com menor evidência, nos exemplares com até $15,0 \mathrm{~mm}$ de diâmetro do disco (Fig. 12).

Entre a escama centrodorsal e a margem do disco, na região interradial, verificaram-se 9 a 10 escamas no indivíduo com diâmetro do disco de $21,45 \mathrm{~mm}, 8$ a 9 escamas naquele com $15,0 \mathrm{~mm}, 7$ a 8 escamas naquele com $10,0 \mathrm{~mm}, 5$ a 6 escamas naquele com $5,0 \mathrm{~mm}$ e 3 escamas no exemplar com $2,5 \mathrm{~mm}$.

Nas Figuras 9-13 observa-se que, à medida que o animal cresce, surgem mais escamas de tamanho e forma irregulares, assim, no exemplar com $21,45 \mathrm{~mm}$ apenas a centrodorsal circular é evidente.
O par de escudos radiais é convergente na região proximal, separado por várias escamas com disposição irregular em cada raio, exceto pela presença de uma escama retangular que toca a regiāo proximal do par de escudos. No espécime menor nāo é possível notar a presença dessa escama. Os escudos radiais nos indivíduos maiores são mais alongados.

A superfície ventral interradial do disco está coberta por escamas pequenas, sendo menores próximo à regiâo oral e fendas bursais. No exemplar com $2,5 \mathrm{~mm}$ a série de escamas maiores da regiāo dorsal interradial é contínua na regiāo ventral, até o escudo oral. Próximo às fendas bursais há uma ou duas séries de escamas menores (Fig. 9).
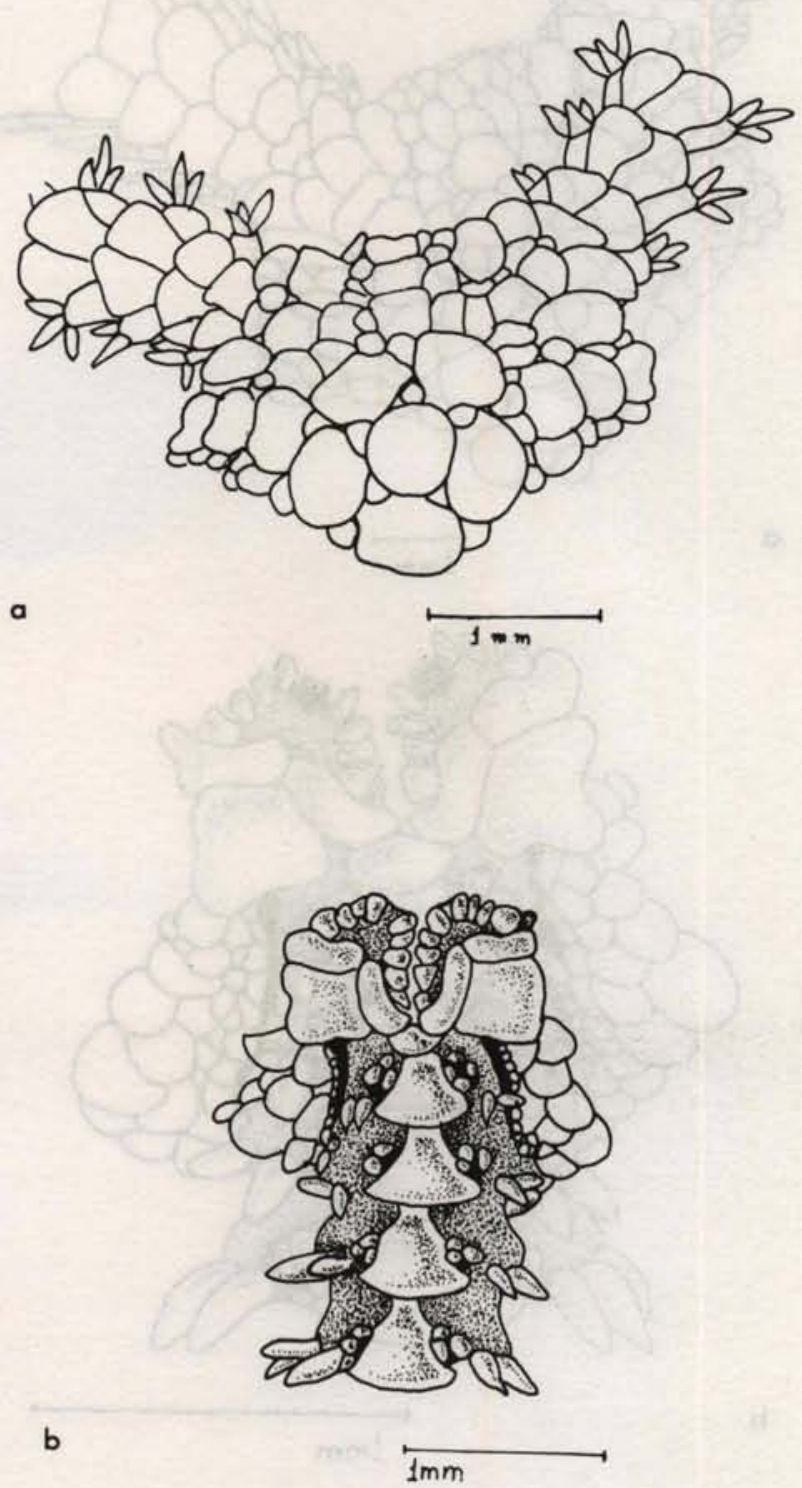

Fig. 9. Vistas dorsal (a) e ventral (b) de Ophioplocus januarii com 2,5 mm de diâmetro do disco. 
$\mathrm{Na}$ maioria Jos exemplares de Ophioplocus januarii verificaram-se quatro papilas orais em cada lado da mandíbula, mas notou-se em um mesmo animal que esse número pode variar para três ou quatro, como pode ser observado nos esquemas dos espécimes com 5,0 - 10,0 e 15,0 mm (Figs 10-12). E possível observar junto à papila distal, uma estrutura semelhante a uma papila afilada, mais interna, que corresponde à borda do poro

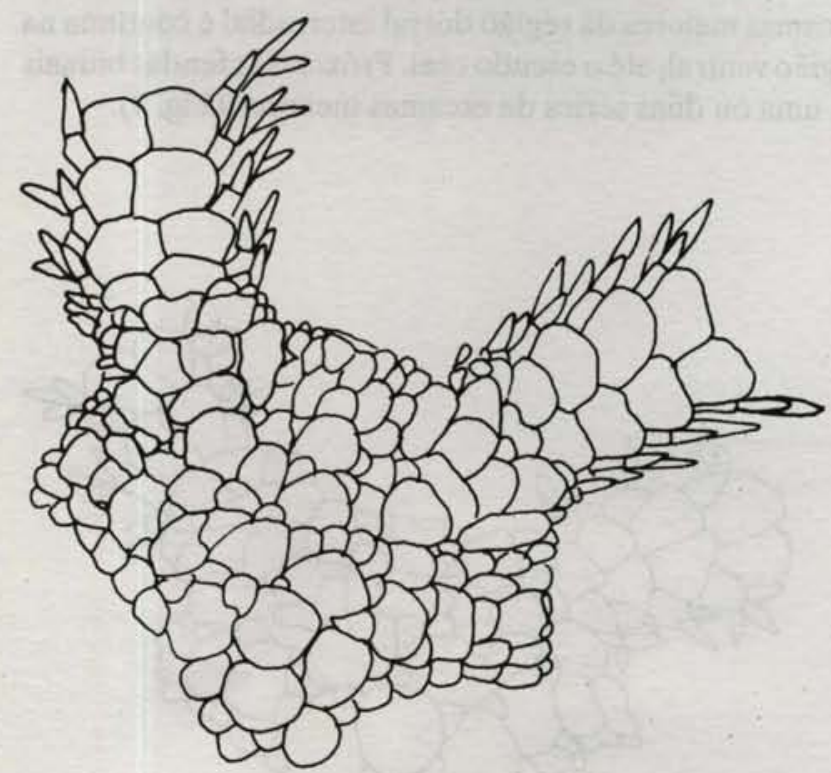

a

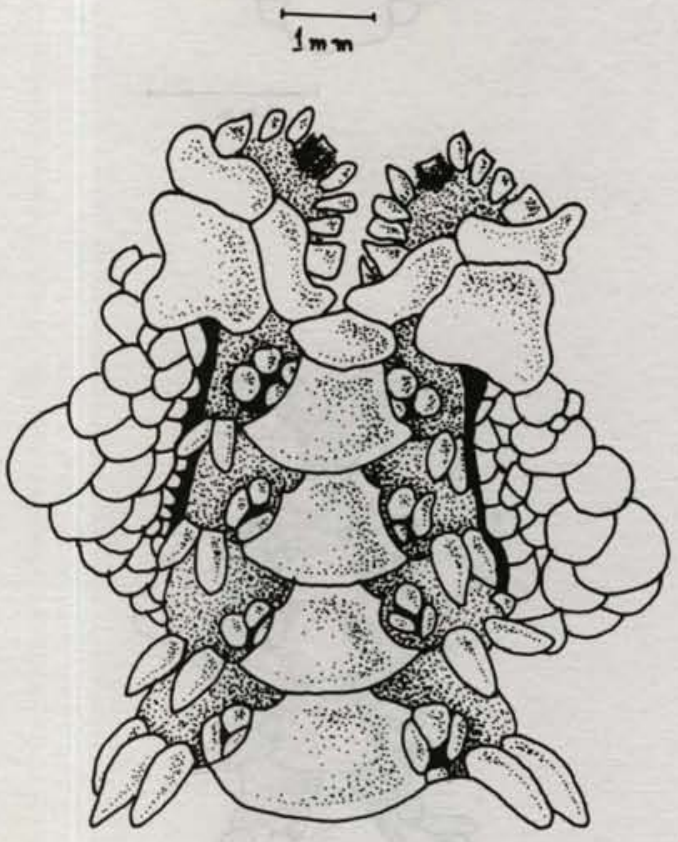

b

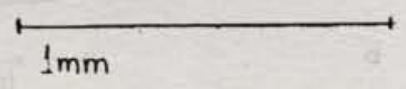

Fig. 10. Vistas dorsal (a) e ventral (b) de Ophioplocus januarii com $5,0 \mathrm{~mm}$ de diâmetro do disco. tentacular e que pode ser confundida com as papilas orais.

Os escudos orais, em forma de raquete, mostraram pequenas variaçôes em animais de diferentes tamanhos. $O$ madreporito é geralmente mais alargado (Fig. 12, exemplar de $15,0 \mathrm{~mm}$ ), apresentando pequenos poros no espécime com 21,45 mm (Fig. 13).

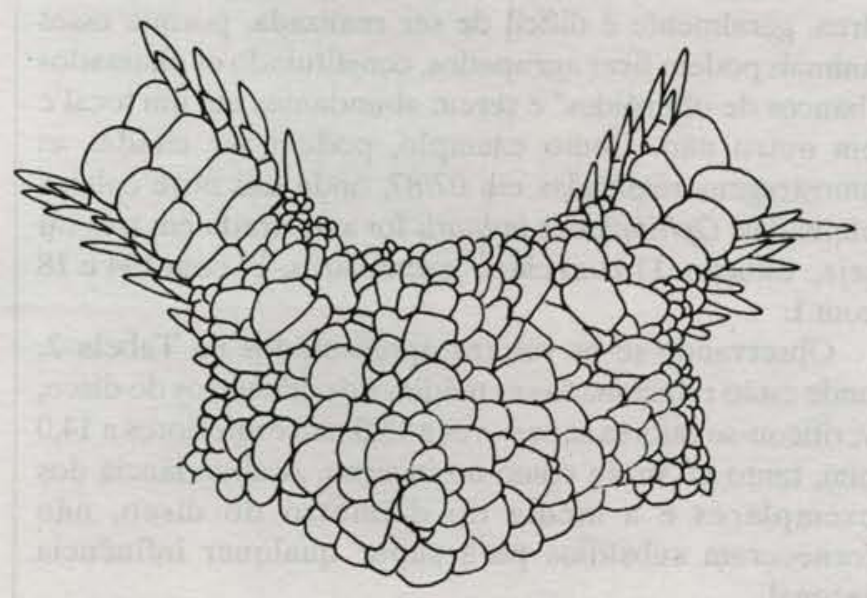

a
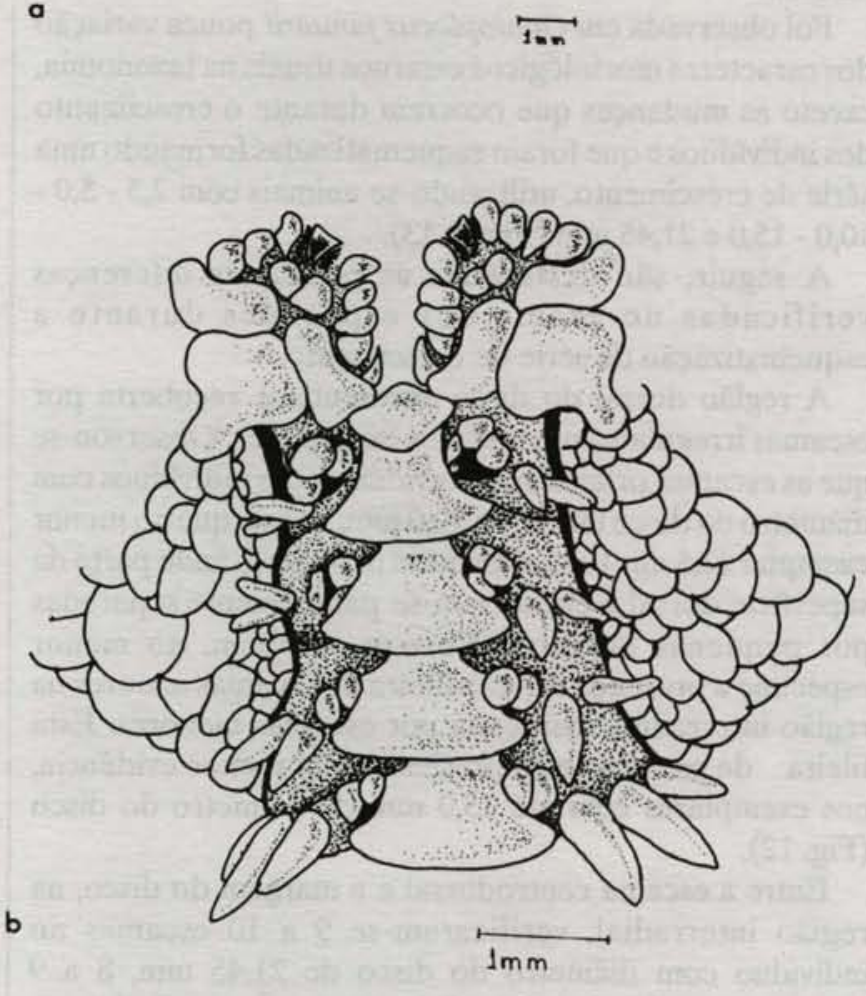

Fig. 11. Vistas dorsal (a) e ventral (b) de Ophioplocus januarii com $10,0 \mathrm{~mm}$ de diâmetro do disco. 

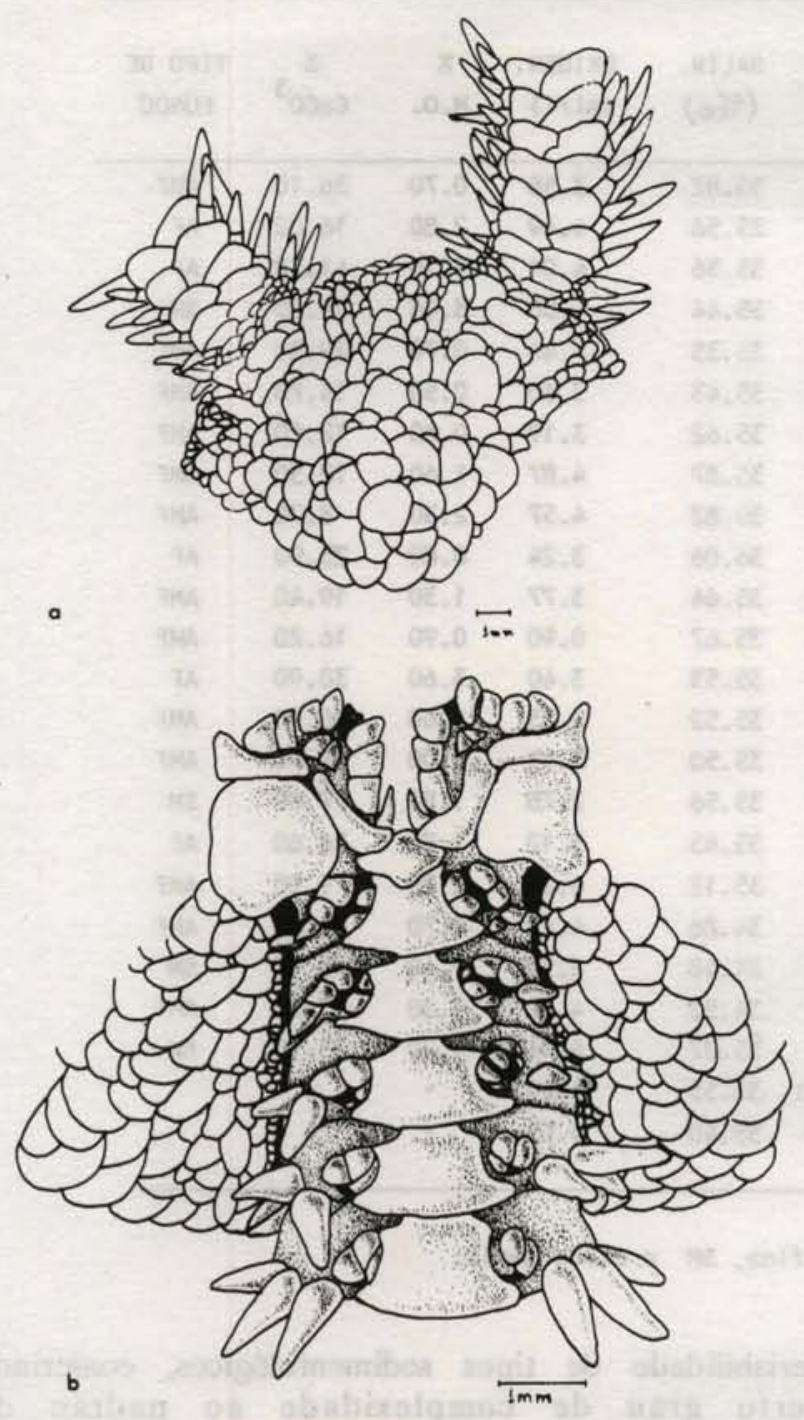

Fig. 12. Vistas dorsal (a) e ventral (b) de Ophioplocus januarii com $15,0 \mathrm{~mm}$ de diâmetro do disco.

Os escudos adorais sāo mais estreitos e geralmente separados anteriormente nos espécimes maiores que 17 $\mathrm{mm}$.

As placas braquiais dorsais são divididas em duas. Em espécimes maiores que $10,0 \mathrm{~mm}$, foram encontradas algumas placas com maior número de divisōes. As braquiais ventrais são semelhantes em exemplares de diferentes tamanhos.

O número de escamas tentaculares é variável de três a cinco nos indivíduos maiores que $10,0 \mathrm{~mm}$ e, de um a quatro nos menores; este número de escamas decresce em direção à extremidade do braço.

A coloração castanha variou de escura a clara, às vezes com manchas irregulares na superfície dorsal do disco. As

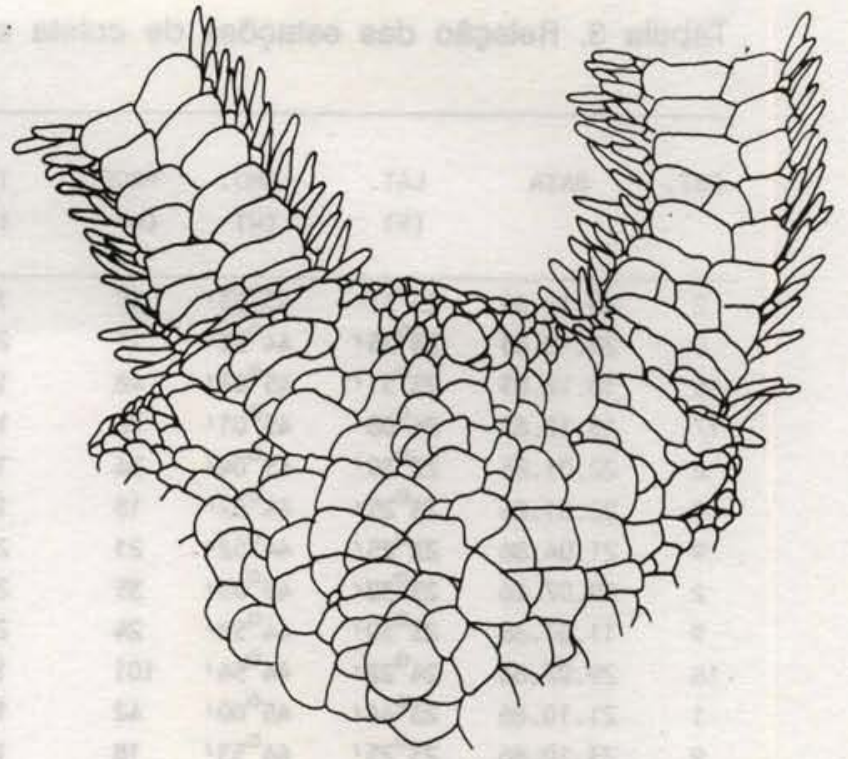

a

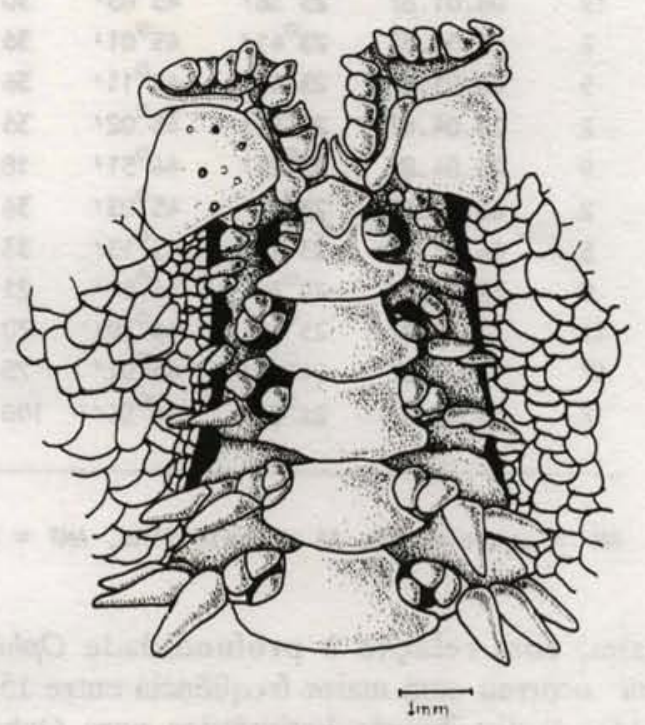

Fig. 13. Vistas dorsal (a) e ventral (b) de Ophioplocus januarii com $21,5 \mathrm{~mm}$ de diametro do disco.

faixas transversais dos braços também são irregulares, ocupando de dois a seis segmentos claros ou escuros.

\section{Parâmetros ambientais}

Analisando-se a distribuição dos ofiuróides estudados em relação aos parâmetros ambientais (Tab. 3), observa-se que existe variação na ocorrência dos mesmos, notando-se que a maior freqüência dos exemplares, muitas vezes ocorreu em valores bem distintos. 
Tabela 3. Relação das estações de coleta e valores dos parâmetros ambientais analisados

\begin{tabular}{|c|c|c|c|c|c|c|c|c|c|c|}
\hline EST. & DATA & $\begin{array}{l}\text { LAT. } \\
\text { (S) }\end{array}$ & $\begin{array}{l}\text { LONG. } \\
\text { (W) }\end{array}$ & $\begin{array}{l}\text { PROF. } \\
(\mathrm{m})\end{array}$ & $\begin{array}{l}\text { TEMP. } \\
\left({ }^{\circ} \mathrm{C}\right)\end{array}$ & $\begin{array}{l}\text { SALIN. } \\
(\% 0)\end{array}$ & $\begin{array}{l}\text { OXIGEN. } \\
(\mathrm{ml} / \mathrm{l})\end{array}$ & $\begin{array}{c}\% \\
\text { M.O. }\end{array}$ & $\mathrm{CaCO}^{3}$ & $\begin{array}{l}\text { TIPO DE } \\
\text { FUNDO }\end{array}$ \\
\hline 2 & 26.10 .85 & $23^{\circ} 37^{\prime}$ & $45^{\circ} 03^{\prime}$ & 35 & 16.79 & 35.82 & 3.58 & 0.70 & 36.10 & AMF \\
\hline 9 & 28.10 .85 & $23^{\circ} 25^{\prime}$ & $44^{\circ} 52^{\prime}$ & 17 & 20.48 & 35.56 & 4.49 & 2.80 & 16.00 & $A F$ \\
\hline 16 & 18.12 .85 & $23^{\circ} 51^{\prime}$ & $45^{\circ} 07^{\prime}$ & 48 & 15.45 & 35.56 & 4.01 & 0.10 & 41.30 & AF \\
\hline 17 & 18.12 .85 & $24^{\circ} 08^{\prime}$ & $45^{\circ} 01^{\prime}$ & 76 & 14.43 & 35.44 & 4.58 & 3.00 & 17.80 & $S M$ \\
\hline 2 & 20.01 .86 & $23^{\circ} 39^{\prime}$ & $45^{\circ} 04^{\prime}$ & 36 & 15.77 & 35.35 & 4.44 & 0.70 & 29.20 & AMF \\
\hline 9 & 22.01 .86 & $23^{\circ} 25^{\prime}$ & $44^{\circ} 52^{\prime}$ & 18 & 18.41 & 35.43 & 3.60 & 0.50 & 14.70 & AMF \\
\hline 9 & 21.04 .86 & $23^{\circ} 25^{\prime}$ & $44^{\circ} 52^{\prime}$ & 21 & 24.78 & 35.62 & 3.19 & 0.80 & 12.00 & AMF \\
\hline 2 & 09.07 .86 & $23^{\circ} 38^{\prime}$ & $45^{\circ} 03^{\prime}$ & 35 & 22.42 & 35.87 & 4.87 & 1.60 & 12.30 & AMF \\
\hline 9 & 11.07 .86 & $23^{\circ} 50^{\prime}$ & $44^{\circ} 52^{\prime}$ & 24 & 22.33 & 35.82 & 4.57 & 2.30 & 8.70 & AMF \\
\hline 18 & 29.07 .86 & $24^{\circ} 22^{\prime}$ & $44^{\circ} 54^{\prime}$ & 101 & 18.13 & 36.06 & 3.24 & 0.80 & 25.90 & AF \\
\hline 1 & 21.10 .86 & $23^{\circ} 44^{\prime}$ & $45^{\circ} 00^{\prime}$ & 42 & 17.99 & 35.64 & 3.77 & 1.30 & 19.40 & AMF \\
\hline 9 & 23.10 .86 & $23^{\circ} 25^{\prime}$ & $44^{\circ} 53^{\prime}$ & 18 & 18.80 & 35.67 & 0.90 & 0.90 & 16.20 & AMF \\
\hline 1 & 07.01 .87 & $23^{\circ} 44^{\prime}$ & $44^{\circ} 59^{\prime}$ & 47 & 15.88 & 35.53 & 3.40 & 3.60 & 38.90 & AF \\
\hline $1 a$ & 08.01 .87 & $23^{\circ} 36^{\prime}$ & $45^{\circ} 03^{\prime}$ & 30 & 16.40 & 35.52 & 2.83 & 1.60 & 18.90 & AMF \\
\hline 2 & 07.01 .87 & $23^{\circ} 41^{\prime}$ & $45^{\circ} 01$ ' & 36 & 15.81 & 35.50 & 3.41 & 3.00 & 18.90 & AMF \\
\hline 5 & 06.01 .87 & $23^{\circ} 47^{\prime}$ & $45^{\circ} 11^{\prime}$ & 36 & 17.21 & 35.56 & 2.78 & 1.80 & 17.60 & $S M$ \\
\hline 2 & 22.04 .87 & $23^{\circ} 41^{\prime}$ & $45^{\circ} 02^{\prime}$ & 36 & 18.68 & 35.45 & 3.12 & 1.30 & 56.60 & AF \\
\hline 9 & 23.04 .87 & $23^{\circ} 25^{\prime}$ & $44^{\circ} 51^{\prime}$ & 18 & 25.17 & 35.12 & 4.28 & 2.20 & 9.00 & AMF \\
\hline 2 & 05.07 .87 & $23^{\circ} 41^{\prime}$ & $45^{\circ} 03^{\prime}$ & 36 & 20.81 & 34.86 & 4.42 & 0.70 & 26.70 & AMF \\
\hline 5 & 04.07 .87 & $23^{\circ} 46^{\prime}$ & $45^{\circ} 13^{\prime}$ & 33 & 20.78 & 34.48 & 4.58 & 1.40 & 15.90 & SM \\
\hline 9 & 02.07 .87 & $23^{\circ} 25^{\prime}$ & $44^{\circ} 51^{\prime}$ & 21 & 20.64 & 34.52 & 4.52 & 1.30 & 13.30 & AMF \\
\hline 11 & 17.07 .87 & $23^{\circ} 49^{\prime}$ & $44^{\circ} 39^{\prime}$ & 70 & 16.96 & 35.37 & 4.04 & 0.20 & 23.50 & AM \\
\hline 17 & 19.07 .87 & $24^{\circ} 08^{\prime}$ & $45^{\circ} 01^{\prime}$ & 75 & $16.97 !$ & 35.55 & 4.09 & - & - & - \\
\hline 18 & 19.07 .87 & $24^{\circ} 22^{\prime}$ & $44^{\circ} 54^{\prime}$ & 100 & 15.85 & 35.40 & 4.03 & - & - & - \\
\hline
\end{tabular}

AM = areia média, $A F=$ areia fina, $A M F=$ areia muito $f$ ina, $S M=$ silte médio.

Assim, com relaçāo à profundidade Ophioderma januarii ocorreu com maior freqüência entre 15 e $18 \mathrm{~m}$ (Fig. 14). A distribuição batimétrica para Ophioderma januarii é dada por Tommasi (1970) como sendo desde a zona de marés até $30 \mathrm{~m}$ e estendida por Albuquerque (1986) até $118 \mathrm{~m}$. Os vários autores que coletaram Ophioderma januarii, mencionaram que obtiveram-na em fundos arenosos ou lodosos. Para Ophioplocus januarii a maior freqüência foi obtida entre 70 e $80 \mathrm{~m}$, mas com alta densidade entre 40 e $50 \mathrm{~m}$ (Fig. 15). Segundo Tommasi (1970) Ophioplocus januarii está distribuída desde a zona de marés até $182 \mathrm{~m}$ de profundidade. Monteiro (1987) coletou-a a $30 \mathrm{~m}$, e citou valores de alguns parâmetros ambientais semelhantes aos obtidos neste trabalho. $\mathrm{O}$ tipo de fundo onde esta espécie foi registrada pelos autores mencionados, varia desde lodo a fundos duros.

A granulometria do sedimento de fundo nos locais onde as duas espécies foram amostradas, variou de silte médio a areia muito fina. Furtado \& Mahiques (1990) mencionaram que a plataforma continental norte do Estado de São Paulo é marcada por grande variabilidade de tipos sedimentológicos, conferindo certo grau de complexidade ao padrāo de sedimentação na área. Há um domínio de areias finas e muito finas na plataforma continental. As enseadas atuam como retentores naturais de pelitos devido às condiçōes de circulação restrita nela existentes. O mecanismo principal de aporte de pelitos para a plataforma pode estar associado à saída de água costeira induzida pela penetração da ACAS. O domínio de termos siltosos sobre os argilosos parece estar afeito ao sistema incipiente de drenagem na área, bem como à composição litológica das áreas emersas adjacentes.

Em relação à temperatura, Ophioderma januarii ocorreu em valores entre 15,77 e $25,17^{\circ} \mathrm{C}$, mas foi mais freqüente entre 17 e $19^{\circ} \mathrm{C}$ (Fig. 16). Ophioplocus januarii foi amostrada em locais com temperaturas menores, entre $14,33 \mathrm{e} 18,66^{\circ} \mathrm{C}$ (Fig. 17).

As salinidades obtidas durante o período de estudo variaram muito pouco, entre 34,36 e $35,91 \%$, o que impossibilitou análises mais detalhadas. 


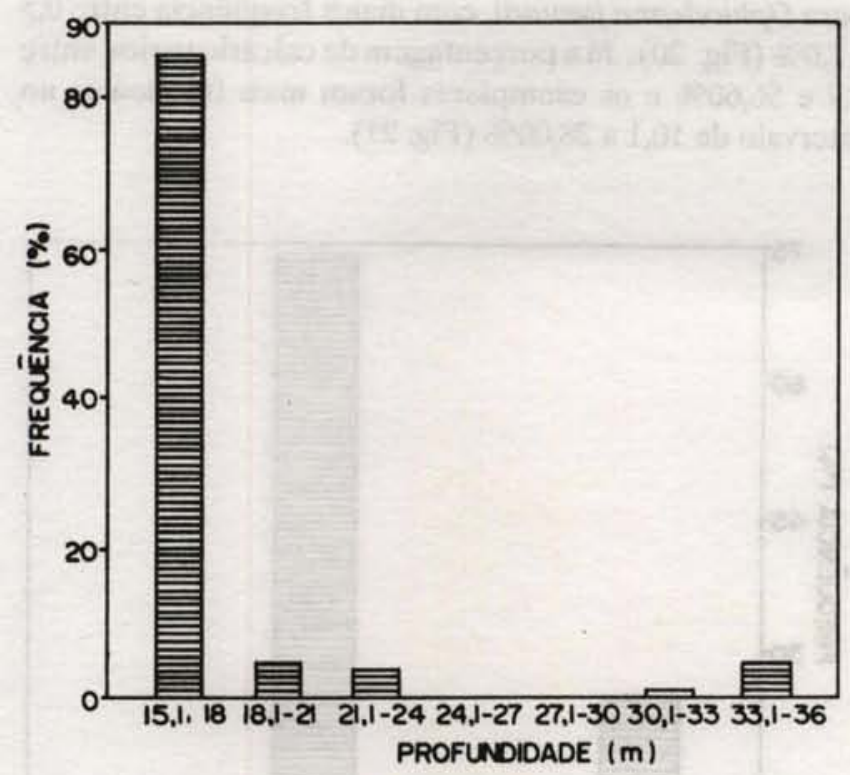

Fig. 14. Distribuição da freqüência de Ophioderma januarii em classes de profundidade.

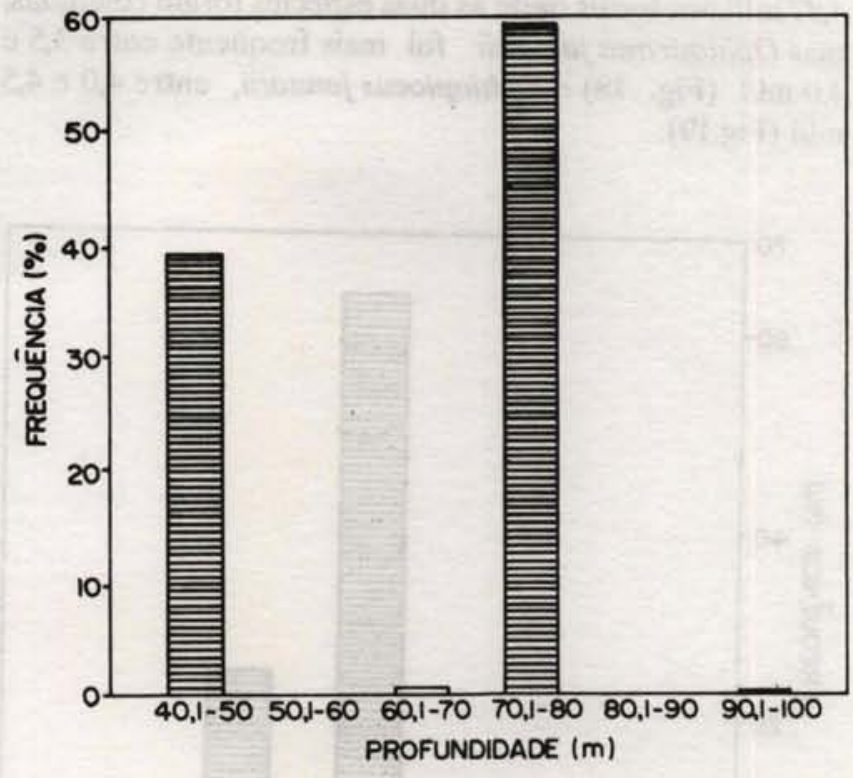

Fig. 15. Distribuição da freqüência de Ophioplocus januarii em classes de profundidade.

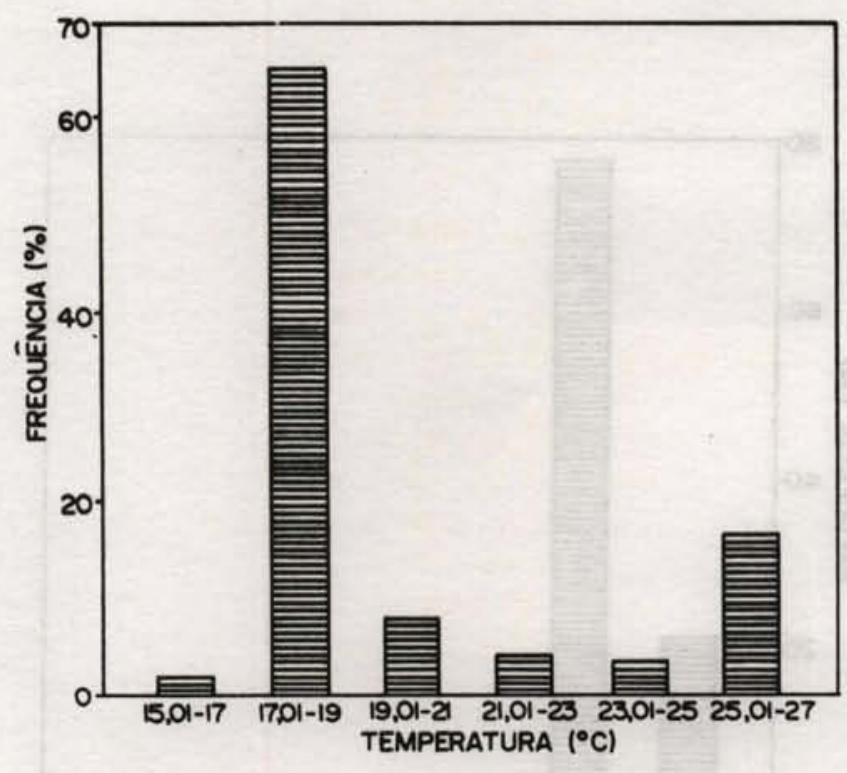

Fig. 16. Distribuição da frequaência de Ophioderma januarii em classes de temperatura.

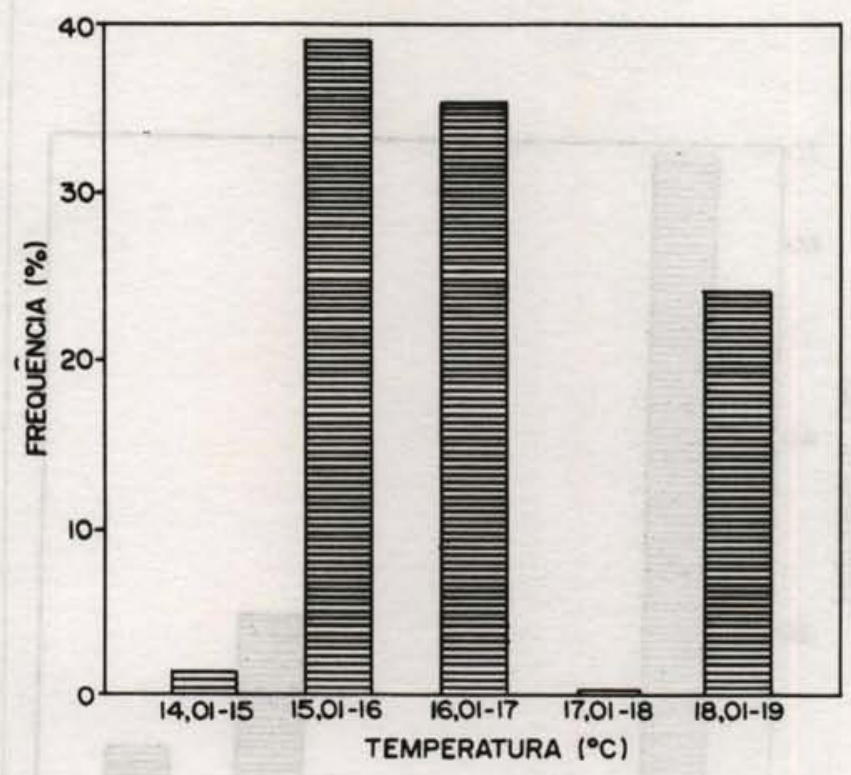

Fig. 17. Distribuição da freqüência de Ophioplocus januarii em classes de temperatura. 
Os teores de oxigênio dissolvido variaram entre 2,58 e $4,87 \mathrm{ml} / 1$ nos locais onde as duas espécies foram coletadas, mas Ophioderma januarii foi mais freqüente entre 3,5 e $4,0 \mathrm{ml} / 1$ (Fig. 18) e Ophioplocus januarii, entre 4,0 e 4,5 $\mathrm{ml} / 1$ (Fig.19).

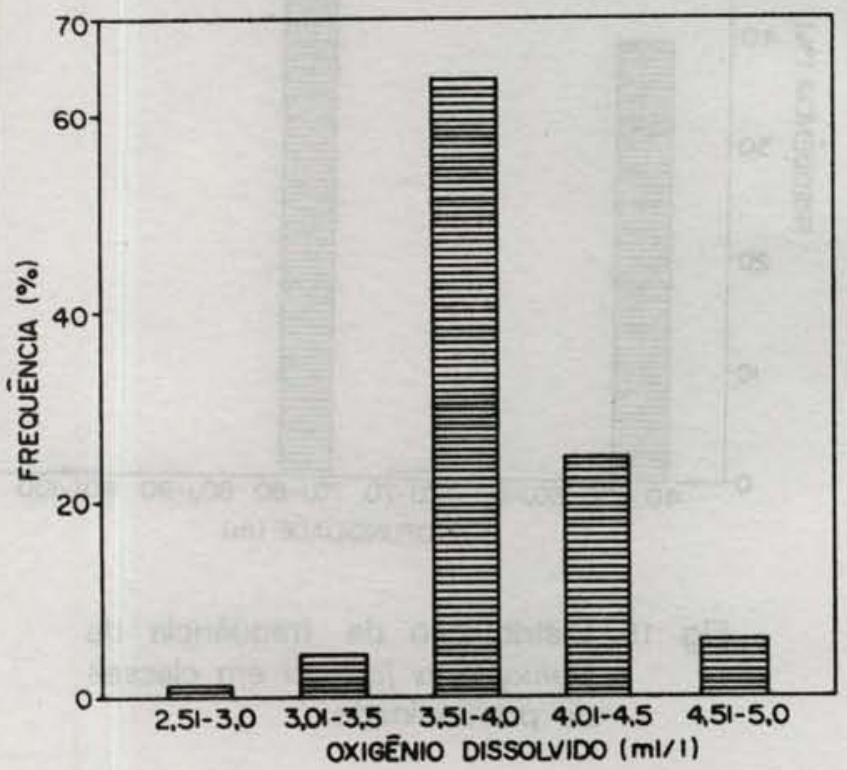

Fig. 18. Distribuição da frequiência de Ophioderma januarii em classes de oxigênio dissolvido.

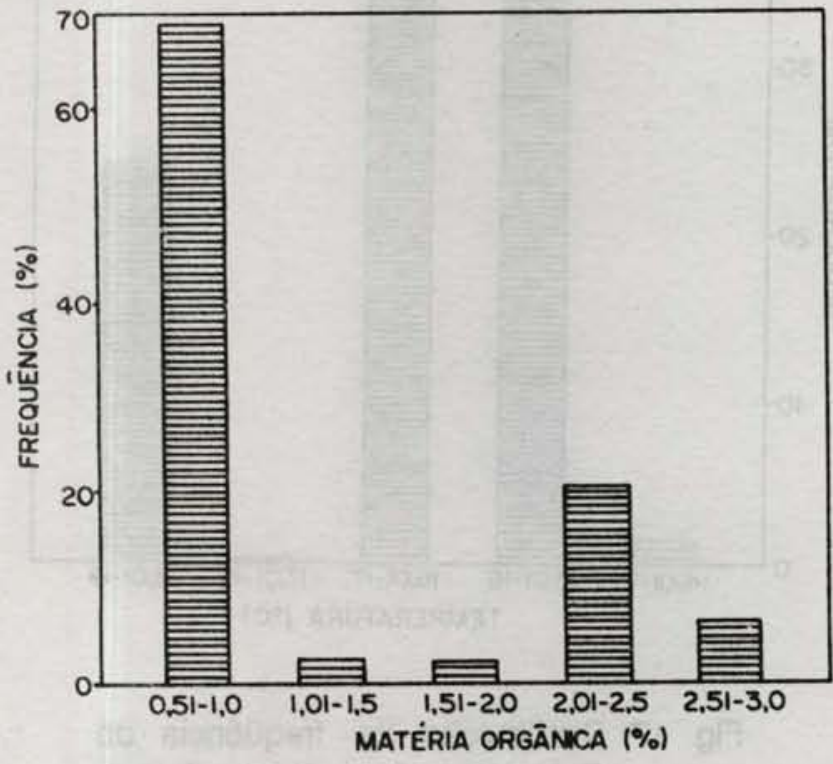

Fig. 19. Distribuição da freqüência de Ophioplocus januarii em classes de oxigênio dissolvido.
O conteúdo de matéria orgânica variou de 0,50 a 2,30\% para Ophioderma januarii, com maior freqüência entre 0,5 a 1,0\% (Fig. 20). Já a porcentagem de calcário variou entre 8,7 e $56,60 \%$ e os exemplares foram mais freqüentes no intervalo de 10,1 a $28,00 \%$ (Fig. 21).

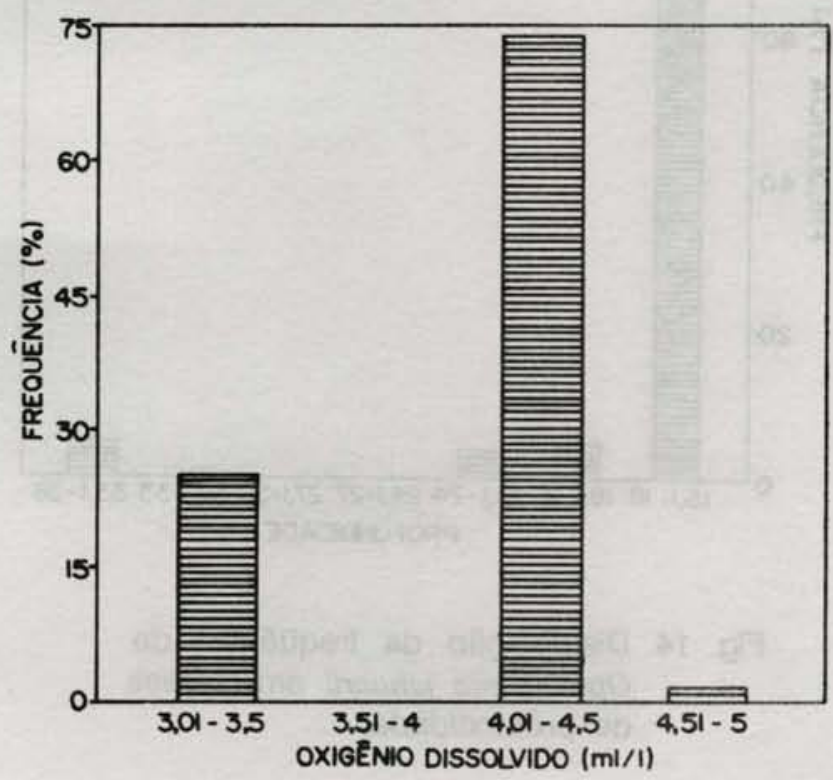

Fig. 20. Distribuição da frequêencia de Ophioderma januarii em classes de teores de matéria orgânica.

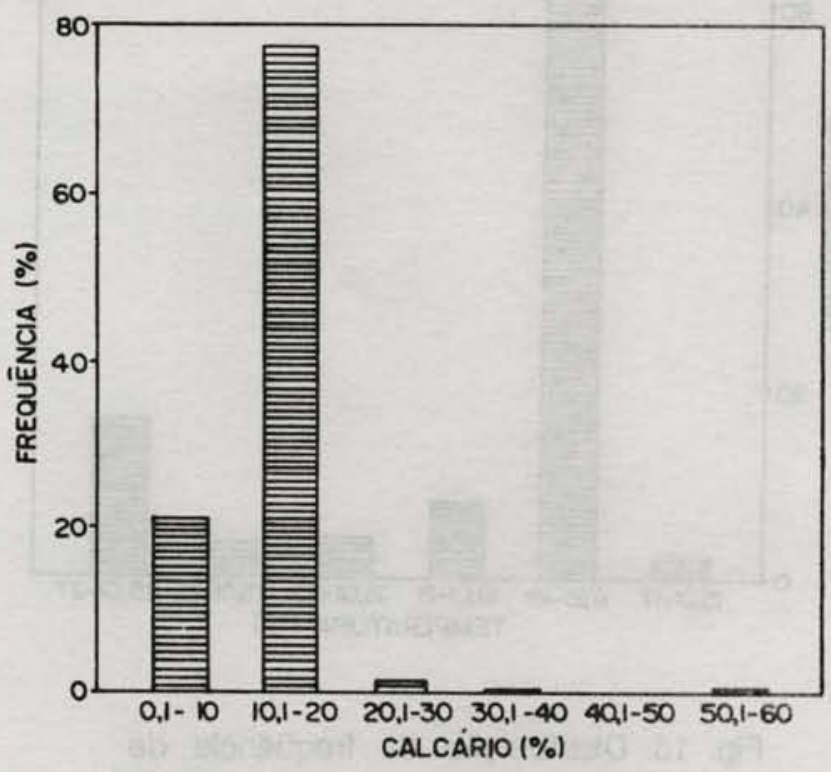

Fig. 21. Distribuição da frequeência de Ophioderma januarii em classes de teores de matéria orgânica. 
Tendo em vista que Ophioplocus januarii foi amostrada em nove coletas, que nas estaçōes 17 e $18(07 / 87)$ nāo foram realizadas análises do sedimento e que ocorreu grande número de espécimes na 17, não foram confeccionados gráficos com a freqüência dos exemplares para os parâmetros relativos a sedimento.

Conforme análise da ocorrência de Ophioderma januarii e Ophioplocus januarii e os resultados dos parâmetros ambientais medidos, observa-se que essas espécies habitam ambientes distintos na região em apreço.

Ophioderma januarii ocorreu na área da plataforma interna, isto é, na área costeira limitada pela isóbata de 50 me Ophioplocus januarii ocorreu próximo à Illha da Vitória em duas estaçōes e na área da plataforma externa, isto é, na área além da isóbata de $50 \mathrm{~m}$.

Registros anteriores na regiāo (Tommasi,1970 e 1985; Monteiro,1987) indicam a ocorrência de Ophioderma januarii em profundidades inferiores a $30 \mathrm{~m}$ e de Ophioplocus januarii, em superiores a $30 \mathrm{~m}$.

\section{Conclusões}

Ophioderma januarii e Ophioplocus januarii ocorrem com freqüência em redes-de-arrasto de fundo na plataforma continental do Estado de São Paulo.

O diâmetro do disco de Ophioderma januarii variou entre 10,5 e 21,5 mm e de Ophioplocus januarii entre 2,6 e $21,5 \mathrm{~mm}$, a medida de $2,6 \mathrm{~mm}$ é a menor registrada para esta espécie. A maior freqüência dos exemplares de Ophioderma januarii ocorreu entre 14,1 e $18,0 \mathrm{~mm}$ de diâmetro do disco e de Ophioplocus januarii entre 14,1 e $17,0 \mathrm{~mm}$.

Com relação d̀s estaçōes do ano, maior número de indivíduos de Ophioderma januarii foi obtido na primavera e de Ophioplocus januarii, no inverno.

Foi verificada pouca variação dos caracteres morfológicos externos usuais na taxonomia, exceto as mudanças inerentes ao crescimento dos indivíduos.

Organizando-se a série de crescimento das duas espécies foi possível observar o seguinte:

- Ophioderma januarii - variações na forma dos escudos orais, no número de papilas orais e de espinhos braquiais, na coloração da superfície dorsal do disco e das placas braquiais dorsais;

- Ophioplocus januarii - variações nas escamas primárias, na série de escamas maiores da região interradial dorsal do disco, no número de escamas entre a centro-dorsal e a margem do disco, na forma dos escudos radiais e orais, no número de papilas orais, na coloraçâo da superfície dorsal do disco e das placas braquiais dorsais.

A distribuiçẫo dos exemplares na área estudada, mostrou que as duas espécies ocorreram em áreas com condiçōes ambientais distintas. Ophioderma januarii foi amostrada na região costeira até $36 \mathrm{~m}$ de profundidade e Ophioplocus januarii entre 30 e $100 \mathrm{~m}$, respondendo diferentemente, em termos de freqüência de indivíduos aos vários parâmetros ambientais estudados.

\section{Resumo}

Durante o período de outubro de 1985 a julho de 1987 , foram coletados 722 ofiuróides pertencentes às espécies Ophioderma januarii e Ophioplocus januarii, na costa do Estado de Sāo Paulo.

Realizou-se medidas do diâmetro do disco dos exemplares e estas variaram entre 10,5 e $21,5 \mathrm{~mm}$ para Ophioderma januarii e entre 2,6 e $21,5 \mathrm{~mm}$, para Ophioplocus januarii.

Foram efetuadas observaçōes das características morfológicas externas dos indivíduos e posteriormente, organizadas séries de crescimento, com o intúito de evidenciar possíveis alteraçōes.

Verificou-se para Ophioderma januarii, variações na forma dos escudos, no número de papilas orais e de espinhos braquiais, na coloração da superfície dorsal do disco e das placas braquiais dorsais e para Ophioplocus januarii variações nas escamas primárias, na série de escamas maiores da região interradial dorsal do disco, no número de escamas entre a centro-dorsal e a margem do disco, na forma dos escudos radiais e orais, no número de papilas orais, na coloração da superfície dorsal do disco e das placas braquiais dorsais.

O resultado das análises de parâmetros ambientais dos locais de coleta, mostrou que as duas espécies ocorreram em áreas com condiçōes ambientais distintas. Ophioderma januarii foi amostrada na região costeira até $36 \mathrm{~m}$ de profundidade e Ophioplocus januarii entre 30 e $100 \mathrm{~m}$.

\section{Agradecimentos}

A Derci Anésia Borela, Luiz Fernando Tirapelli e Soraia Fernandes Rodrigues Soares pelo auxilio técnico, durante a realização deste trabalho.

\section{Referências bibliográficas}

ALBUQUERQUE, M. N. 1986. Ophiuroidea Gray, 1840 (Echinodermata) da plataforma continental do norte e nordeste brasileiro. Tese de doutorado. Universidade de São Paulo, Instituto de Biociências. $393 \mathrm{p}$.

BARTSCH, I. 1982. Ophiuroidea (Echinodermata) from the Patagonian shelf. Mitt. Hamb. Zool. Mus. Inst., 79:211-250. 
BERNASCONI, I. \& D'AGOSTINO, M. M. 1977. Ofiuroideos del mar Epicontinental Argentino. Revta Mus.argent.Cienc.nat. Bernardino Rivadavia, Hidrobiol., 5(5):65-114.

BRITO, I. M. 1962. Ensaio de catálogo dos equinodermas do Brasil. Avulso Cent. Estud. zool. Univ. Bras., (13):1-11.

FELL, H. B. 1960. Synoptic keys to the genera of Ophiuroidea. Zoology Publs, Vict. Univ., Wellington, (26):1-14.

FURTADO, V. V. \& MAHIQUES, M. M. 1990. Distribuição de sedimentos em regiōes costeiras e plataforma continental norte do Estado de São Paulo. In: SIMPÓSIO DE ECOSSISTEMAS DA COSTA SUL E SUDESTE BRASILEIRA: ESTRUTURA, FUNÇĀO E MANEJO, 2., Águas de Lindóia, 1990. São Paulo, Academia de Ciências do Estado de São Paulo. v. 1, p.20-29.

MANSO, C. L. C. 1988a. Sobre a ocorrência de Amphilepis sanmatiensis Bernasconi \& D'Agostino, 1975 na costa sul do Brasil (Echinodermata: Ophiuroidea). Revta brasil. Biol., 48(2):371-373.

1988b. Uma nova especie de Ophiactis (Echinodermata: Stelleroidea) da costa sudeste do Brasil. Revta brasil. Biol, 48(2):375-379.

1988c. Ofiuróides da plataforma continental brasileira. Parte I: Rio de Janeiro (Echinodermata: Ophiuroidea). Revta brasil. Biol., 48(4):845-850.

1988d. Sobre a ocorrência de Ophionema intricata Lutken, 1869 e Ophiophragmus brachiatis H. L. Clark, 1915 no Brasil (Echinodermata, Ophiuroidea, Amphiuridae). Revta brasil. Biol., 48(4):965-968.

1989. Os Echinodermata da plataforma continental interna entre Cabo Frio e Saquarema, Rio de Janeiro, Brasil. Revta brasil. biol., 49(2):355-359.

MONTEIRO, A. M. G. 1987. Ophiuroidea (Echinodermata) da regiâo de Ubatuba (SP) Aspectos morfológicos e ecológicos. Tese de doutorado. Universidade de São Paulo, Instituto Oceanográfico. 166p.

MOURA-BRITO, M. 1985. Stelleroidea da "Operação Sueste I" e das regiōes costeira e estuarina do Estado do Paraná (Echinodermata). Dissertação de mestrado. Universidade Federal do Paraná, Departamento de Zoologia. 78p.
OLIVEIRA, L. 1950. Levantamento biogeográfico da Baía da Guanabara. Mems Inst. Oswaldo Cruz, 48:363-391.

RATHBUN, R. 1879. A list of the Brazilian echinoderms with notes on their distribution. Trans. Conn. Acad. Arts Sci., 5(3):139-158.

TOMMASI, L. R. 1965. Alguns Amphiuridae (Ophiuroidea) do litoral de São Paulo e de Santa Catarina. Contrçōes Inst. oceanogr. Univ. S Paulo, sér. Oceanogr. biol. (8):1-9.

1970. Os ofiur6ides recentes do Brasil e de regiōes vizinhas. Contrçōes Inst. Oceanogr. Univ. S Paulo, sér. Oceanogr. biol., (20):1-146.

1971a. The echinoderms of the Iltha Grande (RJ, Brasil). Distribution and abundance of six species up to the isobath of $50 \mathrm{~m}$. In: Costlow Jr., J.D., ed. Fertility of the sea. New York, Gordon and Breach. v.2, p.581-592.

1971b. Equinodermos do Brasil. II. Equinodermes da Bafa do Trapande, situada no complexo estuarino-lagunar de Cananéia, SP. Bolm Inst. oceanogr., S Paulo, 20:20-23.

1971c. Equinodermes do Brasil. I. Sobre algumas novas espécies e outras pouco conhecidas, para o Brasil. Bolm Inst. oceanogr., S Paulo, 20:1-21.

1974a. Observaçōes sobre a distribuição batimétrica de seis espécies de equinodermes na regiảo da desembocadura do Rio Doce (ES). Revta bras. Biol., 34(2):187-190.

1974b. Equinodermes do Brasil. III. Observaçōes sobre algumas espécies coletadas durante as viagens do N/Oc. "Almirante Saldanha". Bolm Inst. oceanogr., S Paulo, 23:1-15.

1985. Equinodermes da região da Illha da Vitória (SP). Relat. int. Inst. oceanogr., Univ. S Paulo, (13):1-5.

TOMMASI, L. R. \& ABREU, J. 1974. Equinodermes do Brasil. IV. Sobre seis espécies novas de Ophiuroidea da regiāo ao largo da Iliha Grande (RJ). Bolm Inst. oceanogr., S Paulo, 23:17-32.

TOMMASI, L. R. \& ARON, M. A. 1987. Equinodermes dos bancos submarinos da cadeia de montanhas Vitoria-Trindade. Relat. int. Inst. oceanogr., Univ. S Paulo, (18):1-9.

1988. Equinodermes da plataforma continental do sudeste do Estado da Bahia. Relat. int. Inst. oceanogr., Univ. S Paulo, (19):1-6. 
TOMMASI, L. R.; CASTRO, S. M. \& SOUSA, E.
C.P.M.1988a. Echinodermata coletados durante as campanhas oceanográficas do N/Oc. "Almirante Saldanha" no Atlântico Sul Ocidental. Relat. int. Inst. oceanogr. Univ. S Paulo, (21):1-11.

CERNEA, M. C. W. \& CONDEIXA $\bar{M}$. C. G. 1988b. Equinodermes coletados pelo N/Oc."Almirante Saldanha", entre $26^{\circ} 59^{\prime}$ 'S e $38^{\circ} 39^{\prime}$ 'S. Relat int. Inst. oceanogr., Univ. S Paulo, (22):1-11.
TOMMASI, L. R. \& OLIVEIRA, E. 1976. Equinodermes do Brasil. V. Sobre algumas espécies coletadas durante viagens do N/Oc. "Prof. W. Besnard". Bolm Inst. oceanogr., S. Paulo, 25:77-100.

(Manuscrito recebido 5 dezembro 1991; revisto 5 outubro e $1^{2}$ dezembro 1992; aceito 10 dezembro 1992) 